\title{
High-temperature friction behavior of amorphous carbon coating in glass molding process
}

\author{
Kangsen LI ${ }^{1}$, Gang XU ${ }^{1}$, Xiaobin $\mathrm{WEN}^{2}$, Jun ZHOU ${ }^{2}$, Feng GONG ${ }^{1, *}$ \\ ${ }^{1}$ Guangdong Provincial Key Laboratory of Micro/Nano Optomechatronics Engineering, College of Mechatronics and Control \\ Engineering, Shenzhen University, Shenzhen 518060, China \\ ${ }^{2}$ Shenzhen Kingmag Precision Techonology Co. LTD., Shenzhen 518172, China \\ Received: 12 June 2020 / Revised: 15 July 2020 / Accepted: 10 September 2020 \\ (C) The author(s) 2020 .
}

\begin{abstract}
In the glass molding process, the sticking reaction and fatigue wear between the glass and mold hinder the service life and functional application of the mold at the elevated temperature. To improve the chemical inertness and anti-friction properties of the mold, an amorphous carbon coating was synthesized on the tungsten carbide-cobalt (WC-8Co) substrate by magnetron sputtering. The friction behavior between the glass and carbon coating has a significant influence on the functional protection and service life of the mold. Therefore, the glass ring compression tests were conducted to measure the friction coefficient and friction force of the contact interface between the glass and amorphous carbon coating at the high temperature. Meanwhile, the detailed characterization of the amorphous carbon coating was performed to study the microstructure evolution and surface topography of the amorphous carbon coating during glass molding process by scanning electron microscopy (SEM), X-ray photoelectron spectroscopy (XPS), Ramon spectroscopy, and atomic force microscope (AFM). The results showed that the amorphous carbon coating exhibited excellent thermal stability, but weak shear friction strength. The friction coefficient between the glass and coating depended on the temperature. Besides, the service life of the coating was governed by the friction force of the contact interface, processing conditions, and composition diffusion. This work provides a better understanding of the application of carbon coatings in the glass molding.
\end{abstract}

Keywords: glass molding process; high temperature; friction behavior; amorphous carbon coating

\section{Introduction}

With the development of modern science and technology, the glass-based optics, including aspheric lens, gratings, Fresnel lenses, micro-lens arrays, and metalens, have increasing demands in many fields, such as medical diagnosis, biochemical analysis, optical communication, optical imaging, and optical sensor [1-3]. However, the fabrication of glass-based optics with high precision, high efficiency, and low cost is still a challenge and research focus in optical manufacturing. Compared to the traditional and non-traditional machining methods, such as singlepoint diamond cutting, micro-milling, grinding and polishing, ultrasonic-assisted machining, wet/dry etching, and laser machining, precision glass molding has been a cost-effective and high-efficiency method to fabricate glass optics with mass production and high precision [4]. Unfortunately, the service life, chemical inertness, and machining of the mold hinder its wide applications. To satisfy the forming accuracy and reliability of the mold at the elevated

* Corresponding author: Feng GONG, E-mail: gongfeng186@163.com 
temperature, the unique materials, including silicon carbide, WC, and silicon nitrogen, are commonly chosen as mold materials due to the excellent thermal stability, less thermal expansion coefficient, high strength, and high hardness. However, these materials are difficult to be machined, having a sticking reaction with the high-temperature glass.

To reduce the surface sticking reaction between the mold and glass and improve the surface quality and oxidation resistance of the mold, researchers have developed the new protective coatings for glass molding process in recent years. Chen et al. [5, 6] deposited the $\mathrm{Cr}-\mathrm{W}-\mathrm{N}$ and $\mathrm{Ta}-\mathrm{Al}-\mathrm{N}$ coatings on the WC substrates by the reactive direct current magnetron sputtering and investigated the chemical inertness and oxidation resistance of the coatings in the glass molding atmosphere. Lee et al. [7] used the $\mathrm{Al}_{70} \mathrm{Cr}_{30}$ targets to synthesize the $\mathrm{AlCrN}$ coatings in a reactive nitrogen atmosphere and analyzed the surface failure of the coatings. Friedrichs et al. [8] deposited the Pt-Ir coatings on the WC substrates by direct current magnetron sputtering and revealed the degradation mechanism of the coating through detailed characterization. Zhou et al. [9] developed the electroless plated nickel-phosphorus (Ni-P) as a mold material for glass molding. He et al. [10] synthesized the carbide-bonded graphene networks on the Si substrate by chemical vapor deposition and confirmed that the film exhibits an excellent chemical inertness and mechanical properties in glass molding process. In our previous studies [11, $12]$, the $\mathrm{Cr}_{x} \mathrm{~W}_{y} \mathrm{~N}_{z}$ coatings were synthesized on the WC-8Co substrates by plasma-enhanced magnetron sputtering, and the detailed characterization was performed to study the surface evolution and molding performance of the coatings. Among them, carbide-bond films are relatively cost-effective for glass molding protective coatings due to abundant carbon resources.

The amorphous carbon films, such as diamond-like carbon (DLC) and graphite-like carbon (GLC), contain a percentage of $\mathrm{sp}^{3}$ and $\mathrm{sp}^{2}$ bonds $[13,14]$. The DLC films contain $\mathrm{sp}^{3}$ bonds with a structure of diamond, and the GLC films contain a high percentage of $\mathrm{sp}^{2}$ bonds, like graphite. The DLC films commonly exhibit an ultra-high hardness and modulus but poor thermal stability at elevated temperature [15].
The GLC films with a large portion of $\mathrm{sp}^{2}$ bonds have an excellent thermal stability due to the graphite networks [16]. During glass molding process, the coatings endure a coupled interaction of high pressure, shear friction, and high-temperature corrosion. The factors, including the adhesion strength with the substrates, internal stress inside the coatings, and working environment of high-temperature shear friction, still restrict the service life of the coatings in the industry. Although the performance of the amorphous carbon films with a high percentage of $\mathrm{sp}^{2}$ bonds has been optimized recently, there is still unclear mechanism of thermal-displacement coupled interface friction when the film was used in the glass molding. Therefore, it is vital to reveal the hightemperature friction behavior of the amorphous carbon film in the environment of chemical corrosion and high loading [17].

In this work, we synthesized an amorphous carbon coating on the WC-8Co substrates by magnetron sputtering. The precision glass molding machine (PGMM) was employed to fulfill the glass ring compression test. The ring compression test has been validated as one of the most reliable methods for friction evaluation since it is subjected to the realistic conditions of glass molding [18, 19]. By measuring the geometrical shapes, including internal diameter, external diameter, and height, the interface friction coefficient between the coatings and glass was determined. Furthermore, the detailed characterization was performed to study the $\mathrm{sp}^{3} / \mathrm{sp}^{2}$ bond and surface evolution of the coatings. Finally, the friction mechanism between the coating and glass was revealed.

\section{Experiments}

Figure 1(a) shows the schematic of the experimental procedure. The amorphous carbon coating was deposited on the WC-8Co substrates (92 $\mathrm{wt} \% \mathrm{WC}$, and $8 \mathrm{wt} \% \mathrm{Co}$ ) by the magnetron sputtering system (Kingmag, MSTP850/4-Ultra). The graphite target (with the purity of $99.9 \%$ ), and chromium target (with the purity of $99.9 \%$ ) were arranged on the furnace chamber. Before the deposition, the WC-8Co substrates were cleaned in the ethanol and acetone baths with ultrasonic vibration and dried in the vacuum chamber. The background pressure of the 

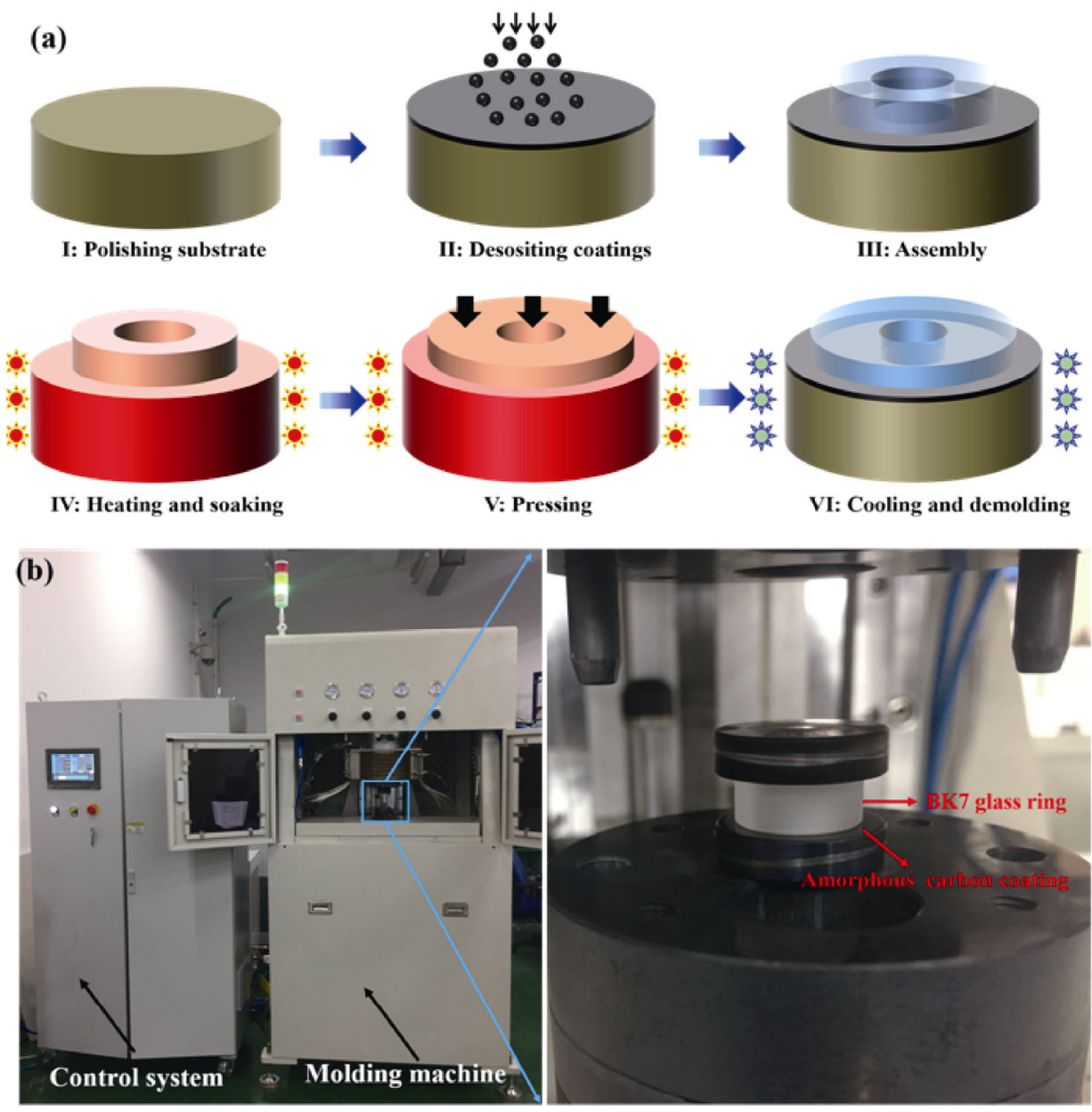

Fig. 1 (a) Schematic of the experimental procedure for glass ring compression test and (b) image of PGMM.

vacuum chamber was evacuated to below $4 \times 10^{-3} \mathrm{~Pa}$, and then Ar gas with a constant flow of $20 \mathrm{sccm}$ was immerged into the furnace chamber. After that, the WC-8Co substrates and targets were in the sputtering cleanout at $0.2 \mathrm{~Pa}$ atmosphere for 15 min. During the deposition process, the transition Cr layer was deposited with $-150 \mathrm{~V}$ bias voltage for $30 \mathrm{~min}$. The amorphous carbon layer was deposited for $300 \mathrm{~min}$ with carbon target. BK7 glass (wt $\%: \mathrm{SiO}_{2}(68 \%), \mathrm{BO}(15 \%), \mathrm{BaO}(6 \%), \mathrm{K}_{2} \mathrm{O}$ $(5 \%)$, and $\mathrm{Na}_{2} \mathrm{O}(6 \%)$ ) were purchased from CDGM Glass Co. Ltd. The glass rings were machined with an internal diameter $\left(d_{\mathrm{i}}\right)$ of $7.11 \mathrm{~mm}$, an outer diameter $\left(d_{0}\right)$ of $14.91 \mathrm{~mm}$, and a height $(h)$ of 5.01 $\mathrm{mm}$. The surface roughness of the glass ring was between 2 and $4 \mathrm{~nm}$.

Molding temperatures were set from 620 to $680{ }^{\circ} \mathrm{C}$ with $20{ }^{\circ} \mathrm{C}$ as space. Molding forces were performed from 200 to 4,000 N. There are three stages, including heating/soaking, pressing, and cooling/demolding in the whole molding process. Figure 1(b) shows PGMM made by our team. The upper mold remained stationary, while the lower mold was driven upward and downward by an AC servomotor system. Firstly, the mold and the glass were heating to the specified temperature $\left(620-680{ }^{\circ} \mathrm{C}\right)$ and soaked for $150 \mathrm{~s}$ to uniform the temperature. Then, the molding force (200-4,000 N) was applied to the mold and compressed the glass rings to the setting position. Finally, when the mold was cooled to the room temperature, release the mold, and measure the size of the molded glass rings.

The surface morphology of the amorphous carbon coating was observed using scanning electron microscopy (SEM, FEI Scios). The chemical compositions of the coatings were identified using EDS (FEI 
Scios) and X-ray photoelectron spectroscopy (XPS, Thermo Electron Inc., K-Alpha+). The $\mathrm{sp}^{3} / \mathrm{sp}^{2}$ bond of the amorphous carbon coatings was characterized by Raman spectra (HORIBA, HR-Revolution) obtained with a laser wavelength of $532 \mathrm{~nm}$. The surface roughness of the amorphous carbon coating was evaluated by AFM (OXFORD MFP-3D Infinity).

\section{Finite element model of glass ring compression}

Coupled thermal-mechanical finite element simulations were performed in Abaqus to obtain the numerical friction calibration curves of the glass ring compression test. Figure 2(a) shows the FEA model, including the glass ring, upper mold, and lower mold. These parts ware defined as deformable bodies and meshed with four-node quadrilateral thermal-mechanical coupled elements. The interface behaviors between master and slave surfaces were treated as the hard contact and Coulomb friction model with penalty formulation. The upper and lower mold surfaces were treated as the master interface, respectively, and the glass surface treated as a slave interface. The mechanical and thermal properties of WC-8Co and BK7 glass are listed in Table 1.

When the molds and glass make contact, the contact heat conductance and gas flow convection were set as 2,800 and $20 \mathrm{~W} /\left(\mathrm{m}^{2} \cdot \mathrm{k}\right)$, respectively. Between transition and softening point, glass material exhibited both elastic and viscous behaviors. The temperature dependency of glass material is mostly treated as Thermally-Rhetorically-Simplicity (TRS) model by the empirical William-Larry-Ferry (WLF) equation [20]. In the cooling stage, the embossed glass lens has a thermal shrinkage due to the temperature drop. The structural relaxation of glass

Table 1 Mechanical and thermal properties of BK7 glass and WC mold.

\begin{tabular}{lcc}
\hline \multicolumn{1}{c}{ Material properities } & BK7 & WC \\
\hline Modulus of elasticity $(\mathrm{MPa})$ & 80,230 & 570,000 \\
Poisson's ratio & 0.206 & 0.2 \\
Density $\left(\mathrm{kg} / \mathrm{m}^{3}\right)$ & 2,500 & 14,650 \\
Thermal conductivity $(\mathrm{W} /(\mathrm{m} \cdot \mathrm{K}))$ & 1.11 & 63 \\
Specific heat $(\mathrm{J} /(\mathrm{kg} \cdot \mathrm{K}))$ & 858 & 314 \\
\hline
\end{tabular}

Table 2 Stress and structural relaxation parameters of BK7 glass.

\begin{tabular}{lcclcc}
\hline \multicolumn{2}{c}{ Stress relaxation properties } & $\begin{array}{l}\text { Structural relaxation } \\
\text { properties }\end{array}$ \\
\hline $\begin{array}{l}\text { WLF shift } \\
\text { constants }\end{array}$ & $C_{1}$ & $C_{2}$ & $\begin{array}{l}\text { Structural relaxation } \\
\text { terms }\end{array}$ & $w_{i}$ & $\tau_{v i}$ \\
& 5.01 & 179.4 & 0.93 & 0.0538 \\
Prony series & $g_{i}$ & $\tau_{i}$ & & 0.07 & 0.0534 \\
& 1.0 & 179.4 & $\begin{array}{l}\text { Activation energy } \\
H / R\end{array}$ & 47,750 \\
Reference & & 680 & Fraction parameter $x$ & & 0.45 \\
temperature $\left({ }^{\circ} \mathrm{C}\right)$ & & & &
\end{tabular}

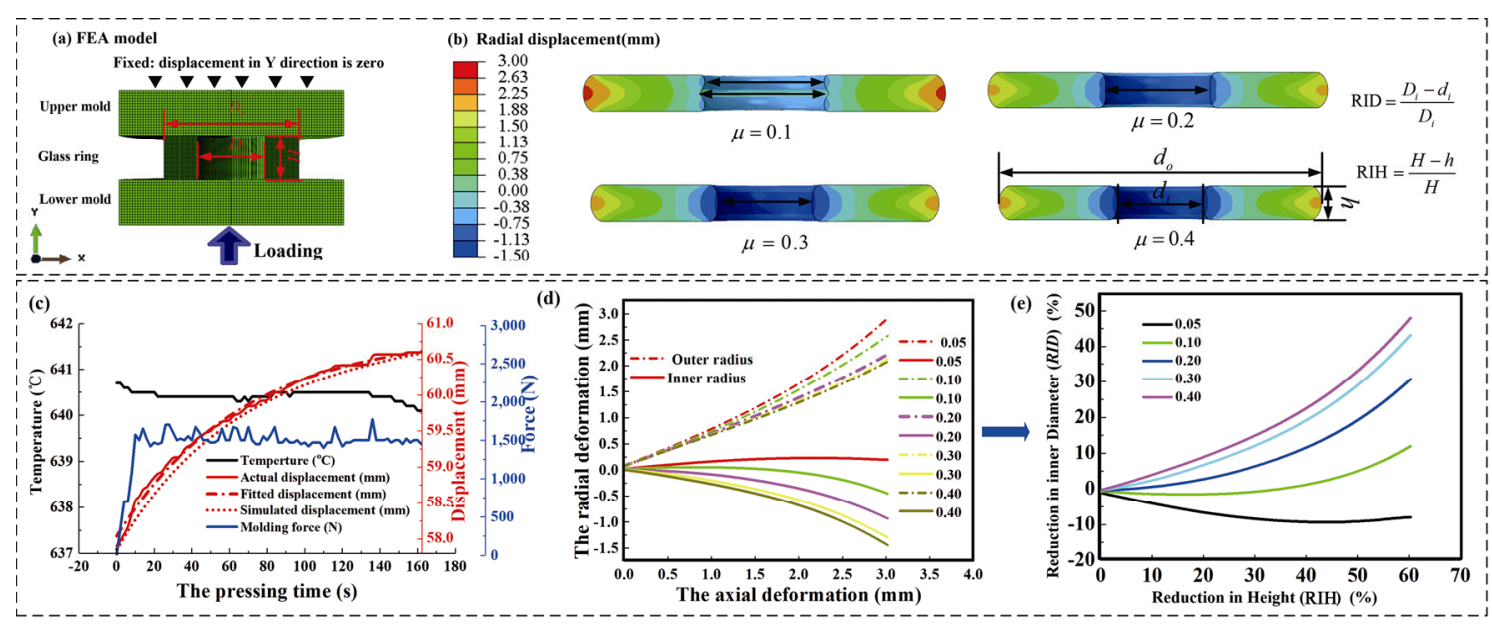

Fig. 2 (a) FEA model used to simulate the glass ring's deformation, (b) radial displacement distribution of the glass ring compression for different interface friction coefficient, (c) comparison of the numerical and experimental displacement during pressing stage, (d) displacement change of the inner and outer diameters at different friction coefficient value, and (e) numerical friction calibration curves under different friction coefficient. 
can be characterized as the Tool-NarayanaswamyMoynihan (TNM) model [21]. The relaxation parameters of BK7 are listed in Table 2 [22].

The friction coefficient between glass and mold has a significant influence on the deformation of the glass ring. If the interface friction coefficient is large, the inner diameter deformation of the glass ring is radially inward. With the interface friction coefficient reduces, the inner diameter deformation of the glass ring gradually trends outward (Fig. 2(b)). Figure 2(c) shows the displacement comparison between the simulation and experimental results at the condition of $640{ }^{\circ} \mathrm{C}$ and $1,500 \mathrm{~N}$. There is a slight deviation between the simulation and experiment due to the experimental error. Nevertheless, the model can be used to predict the deformation process of the molded glass ring at different friction coefficients.

Figure 2(d) shows the radial displacement change versus the axial displacement when the friction coefficient values are set as $0.05,0.1,0.2,0.3$, and 0.4 , respectively. The smaller the friction coefficient value, the more apparent the change in inner radius. When the friction coefficient is around 0.1, the inner radius of the glass ring may decrease or increase, depending on the radial displacement. The softened glass is more likely to flow when the friction is low between the glass and mold, so the outer diameter deformation displacement is large. By calculating the reduction in inner diameter versus reduction in height, the numerical friction calibration curves (FCC) are obtained (Fig. 2(e)).

\section{Results and discussion}

\subsection{Detailed characterization of the amorphous carbon coatings}

To highlight the cross-sectional information of the coatings, focused ion beam (FIB) was used to cut the coatings. Figure 3(a) shows the sectional morphology of the amorphous carbon coating, including the $\mathrm{C}$ layer, $\mathrm{Cr}$ transition layer, and WC-8Co substrate. The thicknesses of the amorphous carbon layer and $\mathrm{Cr}$ layer are about 1,200 and $700 \mathrm{~nm}$, respectively. Besides, it can be seen that lots of nano-phase Co particles diffusely distribute in the WC-8Co substrate, easily leading to the sticking reaction with molten glass. The transition layer $(\mathrm{Cr})$ and amorphous carbon layer can effectively hinder the diffusion-reaction of Co during glass molding. Figures 3(b)-3(f) show the elemental distribution of the amorphous carbon coatings. The detailed distribution of $\mathrm{C}, \mathrm{Cr}$, $\mathrm{Co}$, and $\mathrm{W}$ can be found. The results of the semiquantitative spectrographic analysis show that the contents of $\mathrm{C}, \mathrm{Cr}, \mathrm{Co}, \mathrm{O}$, and $\mathrm{W}$ are $48,10,7,5$, and 30 at $\%$, respectively.

XPS can be used to identify the chemical bonding of the element due to the photoelectric and Auger effects. Figure 4(a) shows the full-scale XPS spectra of the amorphous carbon coating. The element contents of the coating are 92.74 (at\%) C and 7.26 (at\%) $\mathrm{O}$, respectively. The unique chemical bonds of the $C$ element can be easily determined by XPS
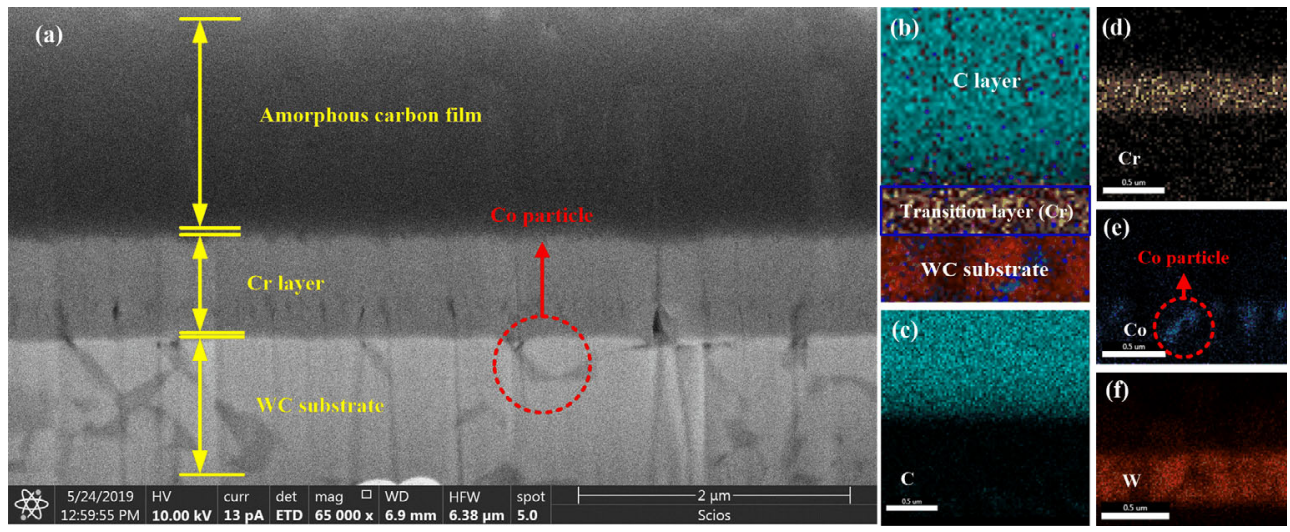

Fig. 3 Section morphology and elemental distribution of the amorphous carbon coating. (a) SEM image of elemental distribution of the amorphous carbon coating, (b-e) elemental distribution of the amorphous carbon coating, including $\mathrm{C}$, $\mathrm{Cr}$, W, and Co. 

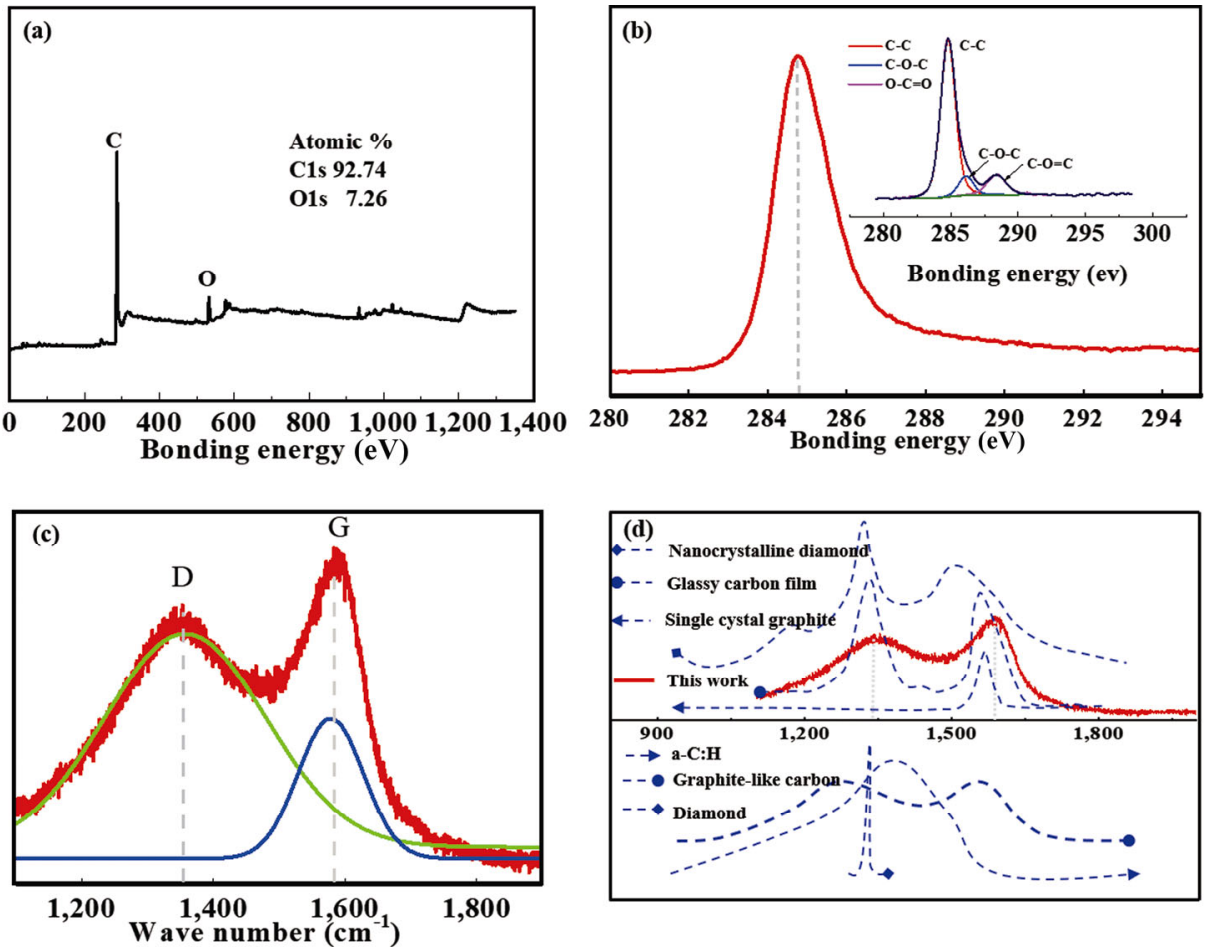

Fig. 4 (a) XPS survey scans for the amorphous carbon coatings, (b) XPS C 1s spectra analysis of the amorphous carbon coatings, (c) Raman spectra of the amorphous carbon coatings, and (d) typical Raman spectra of different carbon films [23-26].

spectroscopy. The C 1s peak of amorphous carbon can be split into four peaks, i.e., the $\mathrm{C}=\mathrm{C}\left(\mathrm{sp}^{2}\right)$ peak at $284.4 \mathrm{eV}, \mathrm{C}-\mathrm{C}\left(\mathrm{sp}^{3}\right)$ peak at $285.2 \mathrm{eV}, \mathrm{C}-\mathrm{O}$ peak at $286.8 \mathrm{eV}$ and $\mathrm{C}=\mathrm{O}$ at $288.5 \mathrm{eV}$. The $\mathrm{C} 1 \mathrm{~s}$ peak position $(285.2 \mathrm{eV})$ of the diamond is about $0.8 \mathrm{eV}$ higher than that of graphite (284.4). Figure 4(b) shows the $C 1$ s spectra acquired from the amorphous carbon coating. The intensity of the bonding energy has a great relationship with the fraction of $\mathrm{sp}^{3}$ and $\mathrm{sp}^{2}$ bonds. It can be seen that a broad and asymmetric tail towards higher binding energy, which indicates the high concentration of the $\mathrm{sp}^{2}$ peak $(284.7 \mathrm{eV})$ of the amorphous carbon coating. In this work, the amorphous carbon coating has a high ratio of $\mathrm{sp}^{2}$, indicating the coating is a graphitelike carbon.

The detailed bonding structure of carbon coating can be analyzed by Raman spectroscopy. Figure 4 (c) shows the Raman spectra of the amorphous carbon coating. The Raman spectrum of carbon coating mainly consists of the $\mathrm{D}$ peak around $1,353 \mathrm{~cm}^{-1}$ and the $G$ peak around $1,580 \mathrm{~cm}^{-1}$ in the wavenumber range of $1,000-2,000 \mathrm{~cm}^{-1}$. The $G$ peak of the amorphous carbon coating is related to the stretching vibration of $\mathrm{sp}^{2}$ atoms in rings and chains, while D peak is due to the breathing mode of $\mathrm{sp}^{2}$ atoms in rings [23]. The intensity ratio value of $\mathrm{I}_{\mathrm{D}} / \mathrm{IG}_{\mathrm{G}}$ is the area ratio of the $\mathrm{D}$ and $\mathrm{G}$ split peaks, which measure through the size of the $\mathrm{sp}^{2}$ phase organized in rings. Figure 4(d) shows the Raman spectra of the nano-crystalline diamond, glassy carbon film, single crystal graphite, a-C:H film, graphitelike carbon, and diamond, vs our work [23-26]. Diamond has a single Raman peak at $1,332 \mathrm{~cm}^{-1}$, which presents a zone center mode of symmetry [25]. The Raman peak of single-crystal graphite occurs at $1,575 \mathrm{~cm}^{-1}$, which is a zone center mode $\mathrm{T}_{2 \mathrm{~g}}$ symmetry. Glassy carbon mold exhibits superior thermal stability, chemical inertness, and compressive strengths, which is suitable for hot embossing process. Glassy carbon film, a form of disordered carbon, presents a level micro-structural disorder between the amorphous carbon and single-crystal graphite [26], as well as thermal stability at high temperatures (above $800{ }^{\circ} \mathrm{C}$ ). a-C:H film, a kind of amorphous carbon, has a peak at around $1,580 \mathrm{~cm}^{-1}$ and exhibits relatively low hardness and poor thermal stability, which is not suitable for glass hot 
embossing. Graphite-like carbon film possesses a graphite-like bonding structure and has a relatively high hardness and wear resistance. In this work, the amorphous carbon film was synthesized by magnetron sputtering. The curves of $D$ and $G$ peaks lay in between the graphite-like carbon and glassy carbon film. The coating possesses mixed the structures of nanocrystalline graphite and graphite-like, which was suited in a high-temperature working environment. Table 3 shows the preparation methods and properties of different advanced glass molding coatings. Compared with other coatings, the amorphous carbon coating still has great potential for glass molding protective coatings due to the thermal stability and low cost of the target.

\subsection{Interface friction coefficient between the coatings and glass at high temperatures}

Friction behavior between the coating interface and glass affects the molding time, molding force, and wear of the coating, which determines the service life of the mold system. It also governs the geometrical shape and shear stress of the molded glass ring. Thus, it is very necessary to investigate the friction coefficient of the contact interface in glass molding. Typical friction evaluation methods include the ball-on-disk, scratch test, double cup extrusion test, and ring compression test. Among them, the ring compression test has simple and apparent advantages such as high inner diameter sensitivity to the friction, approaching actual conditions for glass molding. Figure 5 shows the images of the molded glass rings at different temperatures and deformation heights. To observe the inner diameter change of molded glass rings after cooling stage, the molded glass rings are cut into half by the diamond grinding wheel cutting machine, as shown in Fig. 5(b). The reductions in height displacement are 49.8, 50.4, 49.7, and 50.2\%, respectively. Even though the height deformation of the molded glass rings is dominated by the molding force, molding temperature, and thermal expansion of mold, the displacement deformation of the inner diameter strongly depends on the friction behavior at the coatings/glass interface.

Each geometrical parameter of the molded glass

Table 3 Preparation and properties of different advanced coatings.

\begin{tabular}{|c|c|c|c|}
\hline Advanced coatings & Preparation methods & Properties & $\begin{array}{c}\text { Maximum working } \\
\text { temperature }\left({ }^{\circ} \mathrm{C}\right)\end{array}$ \\
\hline TaAlN [5] & Magnetron sputtering & High oxidation resistance and good chemical inertness & About 650 \\
\hline $\mathrm{AlCrN}[7]$ & Magnetron sputtering & High oxidation resistance and good chemical inertness & About 650 \\
\hline CrWN $[6,11,12]$ & Magnetron sputtering & $\begin{array}{l}\text { High hardness, oxidation resistance, thermal stability, } \\
\text { and good chemical inertness }\end{array}$ & About 700 \\
\hline PtIr [8] & Magnetron sputtering & $\begin{array}{l}\text { High oxidation resistance, thermal stability, and good } \\
\text { chemical inertness }\end{array}$ & About 700 \\
\hline $\mathrm{NiP}[9]$ & Electroplating & Good machinability and chemical inertness & About 500 \\
\hline $\begin{array}{l}\text { Carbide-bonded } \\
\text { graphene }[10]\end{array}$ & $\begin{array}{l}\text { Chemical vapor } \\
\text { deposition }\end{array}$ & $\begin{array}{l}\text { Good thermal stability, chemical inertness, and } \\
\text { electrical properties }\end{array}$ & About 700 \\
\hline DLC [15] & Magnetron sputtering & High hardness & About 450 \\
\hline This work & Magnetron sputtering & Good thermal stability and chemical inertness & About 680 \\
\hline
\end{tabular}
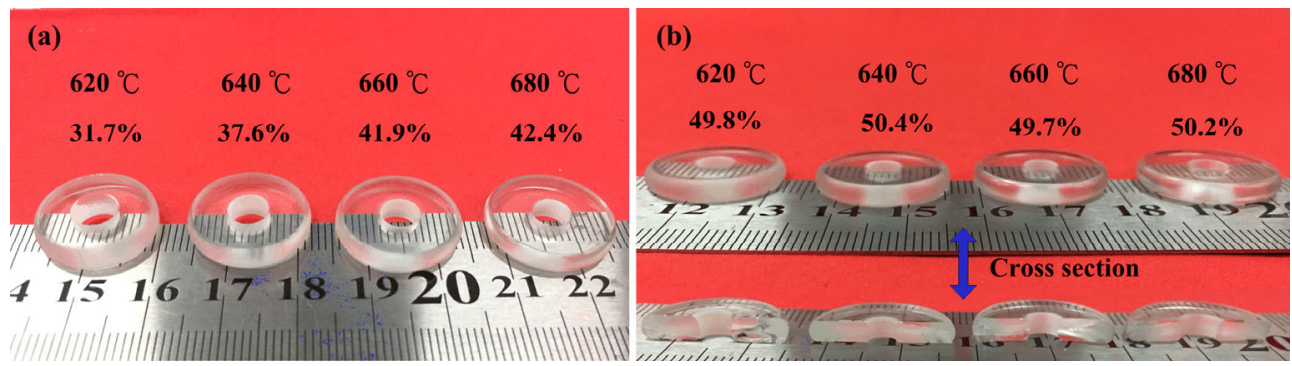

Fig. 5 The molded glass ring at different molding temperature and deformation height. 
rings was measured five times with the data averaged. Since the numerical FCC is fitted by the curves of displacement change of inner diameter and height during pressing stage, the measurements in the molded glass rings have a deviation with the numerical calibration curves. The experimental data of the molded glass rings should be adjusted to compensate for the deviation from the thermal expansion of the mold and the spring back of the machine. Figure 6(a) shows the numerical FCC compared with the experimental data points (label: Exp) and the adjusted data points (label: Adj). By comparing the FCC and adjusted data points, the friction coefficients between the coatings and glass are shown in Fig. 6(b). With the increasing molding temperature, the friction coefficient at the glass/ coating interface reduces. When the temperature is reduced, the deformation resistance and friction resistance of the molded glass ring increase, which results in a larger deformation of inner diameter during pressing stage. As the temperature increases, more free volumes become available, and the deformation resistance and elastic recovery of the mold glass rings decrease. With the increasing timedependent deformation, the radial displacement of the molded glass ring trends to be outward. In our previous study [27], the interface friction coefficient between the PMMA and mold reduces as the molding temperature rises. The trending is similar to this work. It is indicated that the friction behavior of the contact interface has a significant effect on the deformation of the molded ring.

\subsection{Interface friction mechanism between the amorphous carbon coating and glass at the elevated temperature}

The drastic interface friction behavior between the coatings and glass affects the service life and surface morphology of the amorphous carbon coatings. Figure 7(a) shows the image of the coated substrate and glass ring before molding. The surface roughness of the coating is about $5.8 \mathrm{~nm}$. Figure 7(b) shows the wearing coating after several thermal-mechanical cycles. The surface color of the amorphous carbon coating has a significant difference, indicating the coating occurs the different levels of wear. To highlight the anomaly in the wear of surface after several thermal-mechanical cycles, three regions are distinguished on the surface of the amorphous carbon coating. Zone a has the largest contact area with a glass ring before pressing stage; $b$ is the friction and wear zone where the glass ring starts to the motions of shear friction; $\mathrm{c}$ is the wear zone where the glass ring fulfills the hot deformation and has the thermal shrinkage and elastic recovery. Zones $b$ and $c$ have a severe motion of the shear friction, resulting in the different levels of degradation. Figure 7(c) shows the optical image of the friction boundary between Zones a and $b$. Zone $b$ occurs severe degradation, which means the disappearance of the C layer. Figure $7(\mathrm{~d})$ shows the optical image of the friction boundary between Zones $b$ and c. It can be seen that the coating has an apparent gradient of wear due to the interface shear friction.
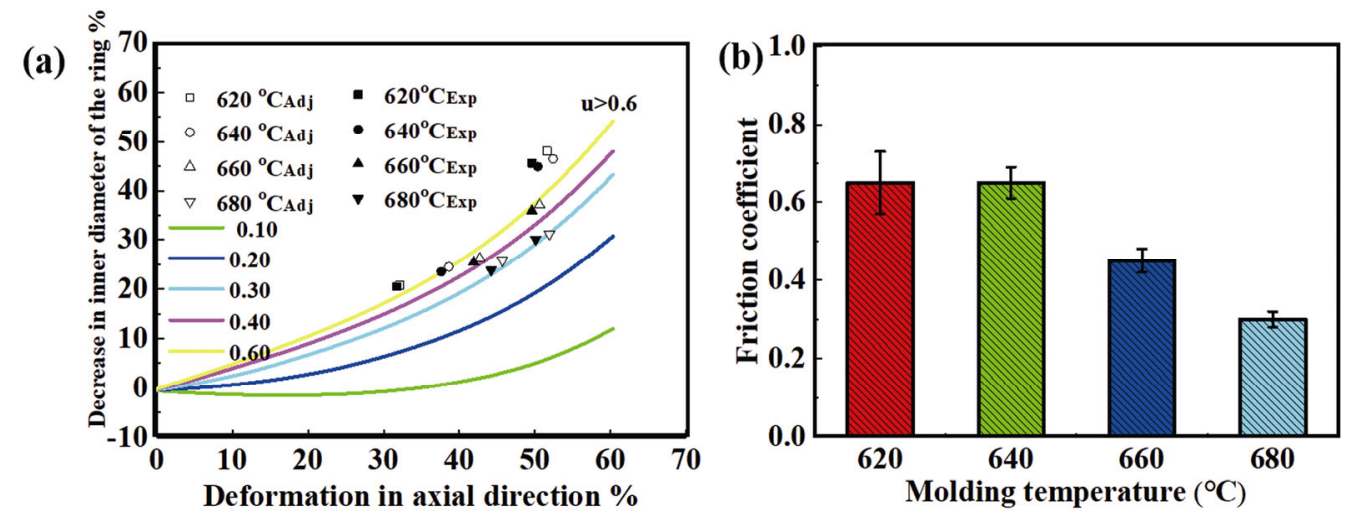

Fig. 6 (a) Numerical friction calibration curves of the glass rings along with experimental data points and (b) the interface friction coefficient at different molding temperature. 


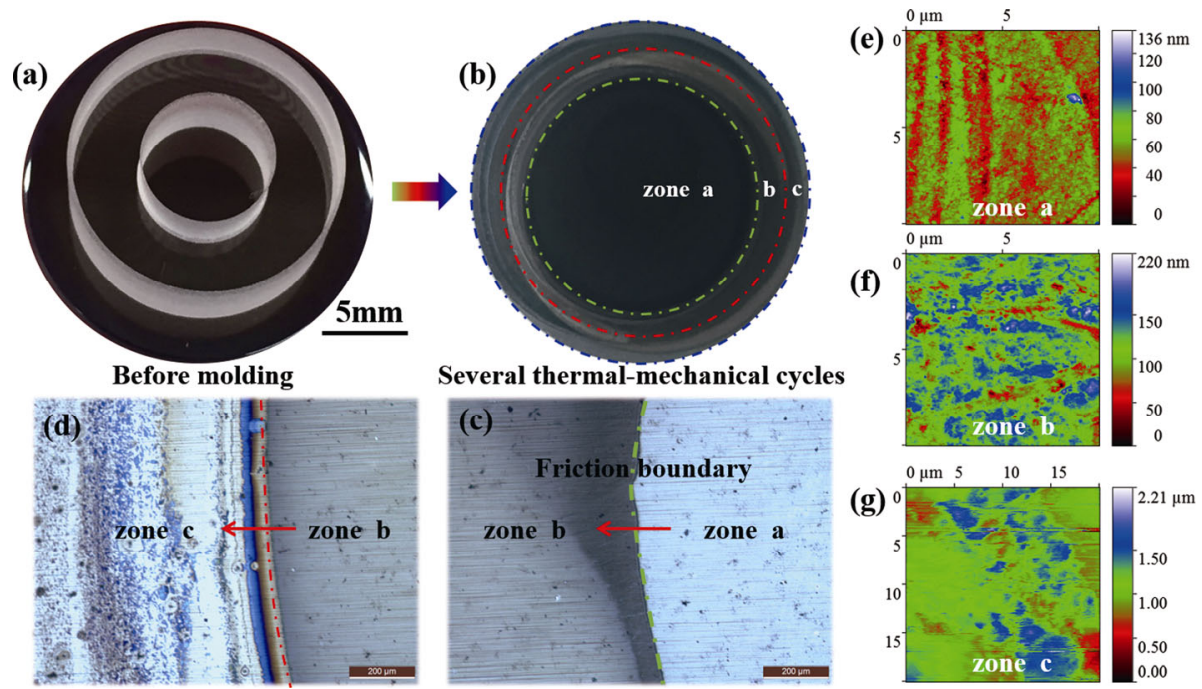

Fig. 7 (a) Image of the coated mold and glass ring before molding, (b) image of the wearing coating after several thermalmechanical cycles, $(c-d)$ optical image of different wearing zones, and (e-g) surface morphology of the different regions.

Figures 7(e-g) show the surface morphology of the three regions. The surface roughness of zone a is slightly higher than that of the initial amorphous carbon coating due to surface roughening, and the value is about $7.6 \mathrm{~nm}$ (Fig. 7(e)). Figure 7(f) shows the surface morphology of the wearing Zone $b$. The wearing region may be the $\mathrm{Cr}$ layer because of the degradation of the $C$ layer. Figure $7(\mathrm{~g})$ shows the surface morphology of Zone $c$, and the value is about $170 \mathrm{~nm}$. The region of severe wear affects the functional application of the mold and the optical quality of the molded glass.

Figure 8(c) shows the image of the molded glass rings. The sticking reaction between the coating and glass affects the optical transmittance of the molded glass, failing of optical performance. The sticking reaction region corresponds to the wear region of Fig. 7(b). Figure 8(c) shows the optical image of the molded glass ring. It can be seen that the friction boundary presents on the surface of the molded glass ring due to the coupled interaction between the interface shear friction and sticking reaction. Zones $\mathrm{b}$ and $\mathrm{c}$ have the different sticking reactions with the mold. The shear friction and sticking reaction at the glass/coating interface affect the service life of the mold and optical quality of the molded glass. To investigate the friction behavior between the coating and glass, the time-history of molding force and displacement are recorded and analyzed, as shown in Fig. 8(a).
The higher the molding temperature is conducted, the less molding force to reach the same set axial displacement is required. The high molding temperature of the glass ring exhibits excellent flowability, so less time is required to reach the same axial deformation. Figure 8(b) shows the friction forces and friction coefficients at the coating/glass interface at different molding temperatures. At lower molding temperature $\left(620^{\circ} \mathrm{C}\right)$, the friction force is high, and the value is about $1,625 \mathrm{~N}$. With the increasing of molding temperature, the friction force sharply reduces. The value of the friction force is about 120 $\mathrm{N}$ at $680{ }^{\circ} \mathrm{C}$, and friction behavior of the contact interface determines the service life of the coatings. Figure 8(e) shows the SEM image of the wearing coating. It can be seen that the coating has a clear friction boundary between the coating and substrate when the amorphous carbon coating experiences serve wear and degradation. The high-temperature wear damage of the coating always occurs at the contact-edge surface of the molded glass ring. At the elevated temperature, the expansions of the substrate, $\mathrm{Cr}$ layer, and C layer have a slight difference, which leads to the increased thermal stress and the reduced the bonding strength of the layers. The higher the molding temperature, the more thermal effect in internal stress. The microcrack and flake delamination quickly occur at the contact edge under the high-temperature contact pressure and cyclic shear stress. 

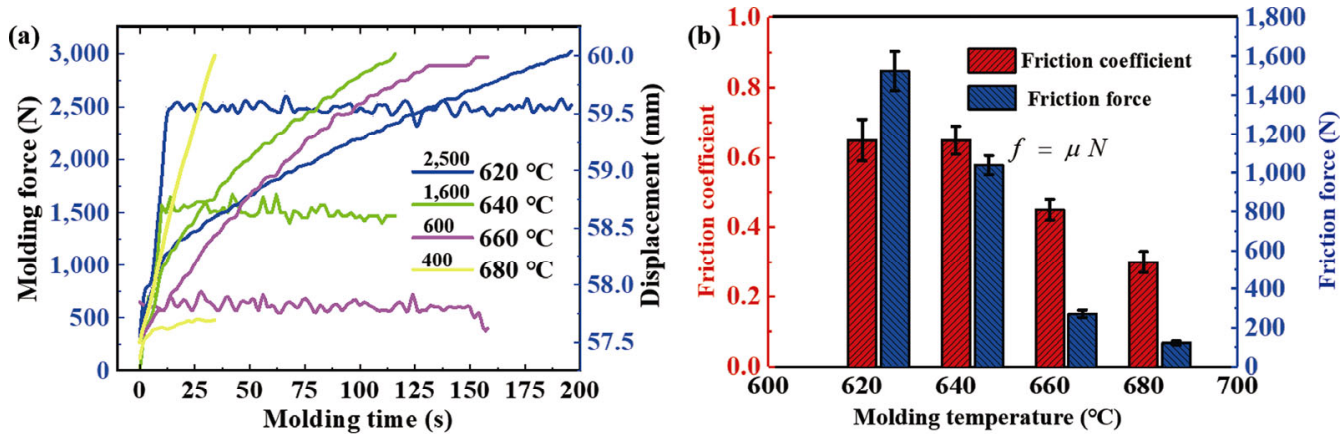

(c)
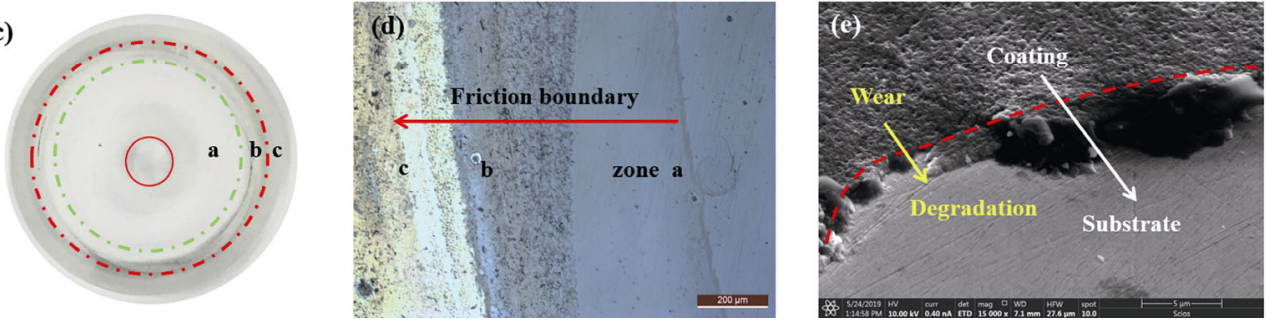

Fig. 8 (a) Time history of the molding force and displacement under different temperature during pressing stage, (b) friction coefficient and force at the coating/glass interface at the different molding temperature, (c) image of the molded glass ring, (d) optical image of the molded glass ring, and (e) SEM image of the wearing coating.

The numerical shear stress distributions of the contact interface at the different molding temperature are shown in Figs. 9(c, d). The shear stress at $680^{\circ} \mathrm{C}$ is far less than that at $620^{\circ} \mathrm{C}$ because the forming stress and friction force of the molded glass ring are smaller at higher molding temperatures. The shear stress distribution is corresponding to the wearing region of the amorphous carbon coating.
Figures 9(a) and 9(b) show the schematic of friction mechanism of the amorphous carbon coating at elevated temperature and high-loading environment. At the initial heating stage, the non-contact area of the coatings was initiated to exhibit the hightemperature oxidation and thermal stress due to the direct exposure of oxygen-containing and hightemperature environment. The glass contact interface

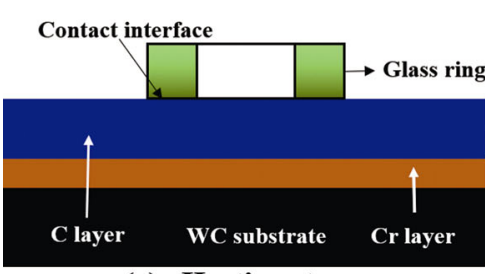

(a) Heating stage

(c) Shear stress (MPa)

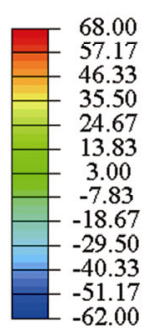

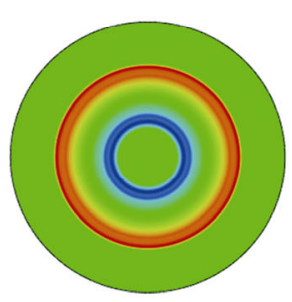

$620{ }^{\circ} \mathrm{C}$

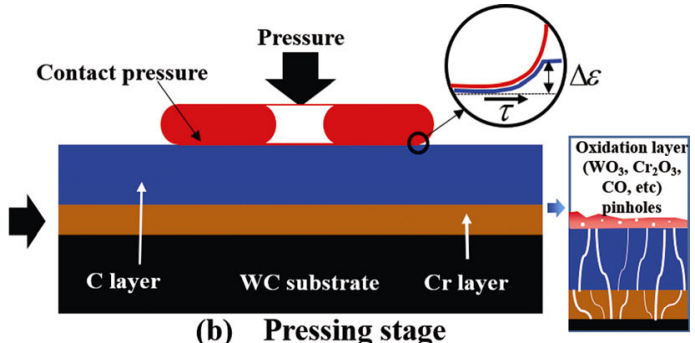

(d) Shear stress (MPa)

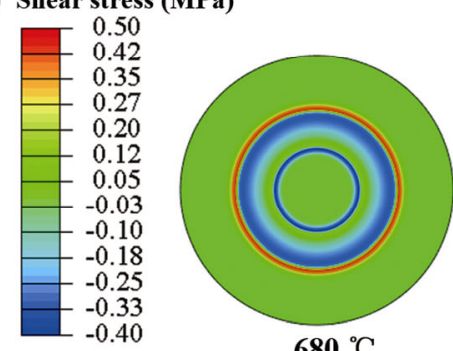

$680{ }^{\circ} \mathrm{C}$

Fig. 9 (a-b) Schematic of friction mechanism of the amorphous carbon coating at elevated temperature and high-loading environment and (c-d) top-surface shear stress distributions of the amorphous carbon coating under the $620 / 680{ }^{\circ} \mathrm{C}$. 
reduces high-temperature oxidized reactions since inhibiting oxygen flow within the molding environment. After a longer heating time, the exposure zone without contacting the glass interface is severely oxidized, resulting in the increased thermal stress of the layers and the degraded mechanical and chemical properties of the coatings. Besides, nanovoids are formed at both surface and inner structure, which roughens the surface morphology of coatings. At the pressing stage, the plastic deformation of the coating increases with the increasing high contact pressure. The high frictional shear stress could destroy the interface adhesion between coating and substrate with the weakness of the mechanical properties of the coating, leading to the wear and degradation of the amorphous carbon coating.

\section{Conclusions}

This work revealed the friction mechanism of the amorphous carbon coatings. The findings can be summarized as follows:

1) The amorphous carbon coatings with graphitelike structures exhibited superior chemical inertness and thermal stability in the glass molding environment, which was a potential protective coating.

2) The friction coefficient at the coating/glass interface was about 0.3 at $680{ }^{\circ} \mathrm{C}$. The friction coefficient and friction force had a significant relationship with the molding temperature. The higher the molding temperature, the smaller the friction force at the coating/glass interface.

3) The shear stress and friction force between the coating and glass affected the service life of the mold. At the lower temperature, the higher shear stress induced the wear and degradation of the coatings. At the higher temperature, the hightemperature oxidation and internal stress of the coating affect mechanical and chemical properties of the coatings, resulting in the degraded coatings.

\section{Acknowledgements}

The authors gratefully acknowledge the financial support of the Natural Science Foundation of Guangdong Province (2018A030313466) and the assistance on the observation received from the Electron Microscope Center of the Shenzhen University.

Open Access This article is licensed under a Creative Commons Attribution 4.0 International License, which permits use, sharing, adaptation, distribution and reproduction in any medium or for-mat, as long as you give appropriate credit to the original author(s) and the source, provide a link to the Creative Commons licence, and indicate if changes were made.

The images or other third party material in this article are included in the article's Creative Commons licence, unless indicated otherwise in a credit line to the material. If material is not included in the article's Creative Commons licence and your intended use is not permitted by statutory regulation or exceeds the permitted use, you will need to obtain permission directly from the copyright holder.

To view a copy of this licence, visit http://creativecommons.org/licenses/by/4.0/.

\section{References}

[1] Chrostowski L. Optical gratings: Nano-engineered lenses. Nat Photonics 4: 413-415 (2010)

[2] Ji S, Song K, Nguyen T B, Kim, Lim H. Optimal Moth Eye Nanostructure Array on Transparent Glass Towards Broadband Antireflection. Acs Appl Mater Inter 5(21): 10731-10737 (2013)

[3] Khorasaninejad M, Chen W T, Devlin R C, Oh J, Zhu A Y, Capasso F. Metalenses at visible wavelengths: Diffraction-limited focusing and subwavelength resolution imaging. Science 352: 1190-1194 (2016)

[4] Li K S, Xu G, Huang X F, Xie Z W, Gong F. Temperature effect on the deformation and optical quality of moulded glass lenses in precision glass moulding. Int J Appl Glass Sci 11: 185-194 (2019)

[5] Chen Y I, Lin J H, Chou C C. Oxidation resistance and mechanical properties of Ta-Al-N coatings. Surf Coat Tech 303: 41-47 (2016)

[6] Chen Y, Cheng Y, Chang L, Lee J. Chemical inertness of $\mathrm{Cr}-\mathrm{W}-\mathrm{N}$ coatings in glass molding. Thin Solid Films 593: 102-109 (2015)

[7] Lee S H, Ko I H, Kim T Y. Surface failure analysis of AlCrN coating on WC substrate subjected to high-temperature oxidation in glass-molding machine. Appl Surf Sci 405: 210-216 (2018)

[8] Friedrichs M, Peng Z, Grunwald T, Rohwerder M, Gault 
B, Bergs T. PtIr protective coating system for precision glass molding tools: design, evaluation and mechanism of degradation. Surf Coat Tech 385: 125378 (2020)

[9] Zhou T, Yan J, Liang Z, Wang X, Kobayashi R, Kuriyagawa T. Development of polycrystalline Ni-P mold by heat treatment for glass microgroove forming. Precis Eng 39: 25-30 (2015)

[10] He P, Li L, Yu J, Huang W, Yen Y C, Lee L J, Yi A Y. Graphene-coated $\mathrm{Si}$ mold for precision glass optics molding. Opt Lett 38(14): 2625-2628 (2013)

[11] Huang X F, Xie Z W, Li K S, Chen Q, Gong F, Chen Y J, Feng B. Microstructure, wear and oxidation resistance of CrWN glass molding coatings synthesized by plasma enhanced magnetron sputtering. Vacuum 174: 109206 (2020)

[12] Li K S, Xu G, Huang X F, Chen Q, Xie Z W, Gong F. Surface evolution analysis of $\mathrm{Cr}_{x} \mathrm{~W}_{y} \mathrm{~N}_{z}$ coatings on $\mathrm{WC}$ mold in glass molding process. Surf Coat Tech 393: 125839 (2020)

[13] Robertson J. Diamond-like amorphous carbon. Mater Sci Eng R 37: 129 (2002)

[14] Huang M, Zhang X, Ke P, Wang A. Graphite-like carbon films by high power impulse magnetron sputtering. Appl Surf Sci 283: 321-326 (2013)

[15] Brand J, Gadow R, Killinger A. Application of diamond-like carbon coatings on steel tools in the production of precision glass components. Surf Coat Tech 180(2): 213-217 (2004)

[16] Balandin A A. Thermal properties of graphene and nanostructured carbon materials. Nat Mater 10(8): 569$581(2011)$

[17] Diao D F, Wang C, Fan X. Frictional behavior of nanostructured carbon films. Friction 1(1): 63-71 (2013)

[18] Ananthasayanam B, Joshi D, Stairiker M, Tardiff M,

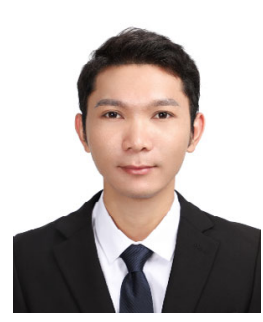

Kangsen LI. He is a Ph.D. candidate of Shenzhen University.

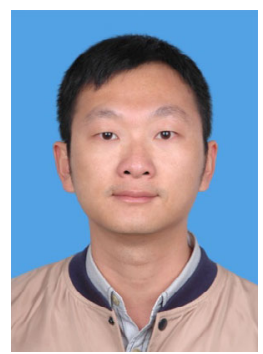

Feng GONG. He is a professor in College of Mechatronics and Control Engineering at Shenzhen University. He received his Ph.D. degree in
Richardson K C, Joseph P F. High temperature friction characterization for viscoelastic glass contacting a mold. J Non-Cryst Solids 385: 100-110 (2014)

[19] Sarhadi A, Hattel J H, Hansen H N. Evaluation of the viscoelastic behaviour and glass/mould interface friction coefficient in the wafer based precision glass moulding. J Mater Process Tech 214(7): 1427-1435 (2014)

[20] Williams D, Landel R F, Ferry J D. The temperature dependance of relaxation mechanisms in amorphous polymers and other glass form liquids. $\mathrm{J} \mathrm{Am} \mathrm{Chem} \mathrm{Soc}$ 77(14): 3701-3707 (1955)

[21] Narayanaswamy O S, Narayanaswamy O S. A Model of Structural Relaxation in Glass. J Am Ceram Soc 54(10): 491-498 (1971)

[22] Jain A, Firestone G C, Yi A Y. Viscosity Measurement by Cylindrical Compression for Numerical Modeling of Precision Lens Molding Process. J Am Ceram Soc 88(9): 2409-2414 (2005)

[23] Ferrari A C, Robertson J. Interpretation of Raman spectra of disordered and amorphous carbon. Phys Rev B 61(20): 14095-14107 (2000)

[24] Chu P K, Li M. Characterization of amorphous and nanocrystalline carbon films. Mater Chem Phys 96(2-3): 253-277 (2006)

[25] Robertson, J. Diamond-like amorphous carbon. Mater Sci Eng R 37: 129-281 (2002)

[26] Wang X, Bao Z X, Zhang Y L, Li F Y, Yu R C, Jin C Q. High pressure effect on structural and electrical properties of glassy carbon. J Appl Phys 93(4): 19911994 (2003)

[27] Li K, Xu G, Huang X, Xie Z, Gong F. Manufacturing of micro-lens array using contactless micro-embossing with an EDM-mold. Appl Sci 9(1): 85-97 (2019)

His main research focuses on glass molding and protective coating. material processing engineering from Harbin Institute of Technology in 2010. His current research focuses on glass molding and micro forming. 